\title{
Food protein-induced enterocolitis syndrome caused by scallop
}

YUKA OKURA $^{1}$, Yutaka Takahashi ${ }^{1}$, and Ichiro Kobayashi ${ }^{1}$

${ }^{1}$ KKR Sapporo Medical Center

December 7, 2021

Title: Food protein-induced enterocolitis syndrome caused by scallop

Authors: Yuka Okura, Yutaka Takahashi, and Ichiro Kobayashi.

Institutional affiliation: Department of Pediatrics, KKR Sapporo Medical Center, Sapporo, Japan

Running title: FPIES caused by scallop

Corresponding author: Yuka Okura, KKR Sapporo Medical Center, Department of Pediatrics, 6-3-40, Hiragishi 1-jo, Toyohira-ku, Sapporo, 062-0931, Japan

Phone: 81-11-822-1811; Facsimile: 81-11-841-4572; E-mail; okura@kkr-smc.com

Word count: 973 words

Tables: 0

Figures: 0

Hosted file

Main text.docx available at https://authorea.com/users/423043/articles/548468-food-proteininduced-enterocolitis-syndrome-caused-by-scallop 